\title{
Investigation of the influence of incremental sheet forming process parameters using response surface methodology
}

\author{
Belouettar Karim ${ }^{1}$, Ould Ouali Mohand ${ }^{2, *}$, Zeroudi Nasereddine ${ }^{1}$, and Thibaud Sébastien ${ }^{3}$ \\ ${ }^{1}$ Laboratoire des Techniques Avancées de Fabrication et Contrôle, LTAFC, Ecole Militaire Polytechnique, Bordj El Bahri, \\ Algiers 16111, Algeria \\ ${ }^{2}$ Laboratoire Élaboration et Caractérisation des Matériaux et Modélisation (LEC2M), Université Mouloud MAMMERI, BP \\ 17RP, Tizi-Ouzou 15000, Algeria \\ ${ }^{3}$ FEMTO-ST Institute, Univ. Bourgogne Franche-Comté, CNRS/UFC/ENSMM/UTBM, Besançon 25000, France
}

Received: 4 January 2021 / Accepted: 28 April 2021

\begin{abstract}
New methods in metal forming are rapidly developing and several forming processes are used to optimize manufacturing components and to reduce cost production. Single Point Incremental Forming (SPIF) is a metal sheet forming process used for rapid prototyping applications and small batch production. This work is dedicated to the investigation of the profile geometry and thickness evolution of a truncated pyramid. The influence of process parameters during a SPIF process is also studied. A numerical response surface methodology with a Design of Experiments (DOE) is used to improve the thickness reduction and the effects of the springback. A set of 16 tests are performed by varying four parameters: tool diameter, forming angle, sheet thickness, and tool path. The Gurson-Tvergaard-Needleman (GTN) damage model is used to analyze the damage evolution during material deformation. It is found that the model can effectively predict the geometrical profile and thickness with an error of less than $4 \%$. Furthermore, it is noticed that the forming angle is the most influential parameter on the thickness reduction and springback level. Finally, the damage evolution is demonstrated to be sensitive to the forming angle.
\end{abstract}

Keywords: single point incremental forming (SPIF) / FE simulation / springback / sheet thickness / response surface methodology / damage evolution

\section{Introduction}

Incremental sheet forming (ISF) is a technology used to obtain complex components. The principle of the technique is to form a sheet by using a hemispherical end tool by localized plastic deformation. The desired geometry is obtained by sweeping the considered area and inducing a forming tool path controlled by a CNC milling machine (Fig. 1). The main advantage of this process is the low cost of tooling development compared to conventional processes like deep drawing [1-3].

An ISF operation can be performed in different ways. A review of these varieties has been presented by Jeswiet et al. [4], Emmens et al. [5], and Li et al. [6]. Among these different types of ISF, the Single Point Incremental Forming (SPIF) is of particular interest and is the focus of this paper.

\footnotetext{
* e-mail: mohand.ouldouali@ummto.dz
}

The final quality of the product depends on several parameters. They can be classified into two main categories: part-related parameters (sheet thickness, product geometry, and material) and tool-related parameters (tool diameter, tool path definition). The study of these parameters influence is crucial for process optimization $[7,8]$.

Several works describe the influence of the different process parameters on the formability in the SPIF process [9-12]. Ambrogio et al. [13] investigate the influence of the incremental forming parameters on geometrical accuracy using experimental and numerical techniques. Ham and Jeswiet [14] present a Design of Experiments and analyze data to find the critical factors affecting SPIF, such as material type, material thickness, formed shape, tool size, and incremental step size. Jeswiet et al. [15] and Duflou et al. [16] discuss the influence of sheet forming forces under SPIF parameters. Guzmán et al. [17] found that the geometrical inaccuracies in a two-slope pyramid formed by SPIF are due to the influence of strain rate and local springback. Ben Hmida et al. [18] show that the forming 

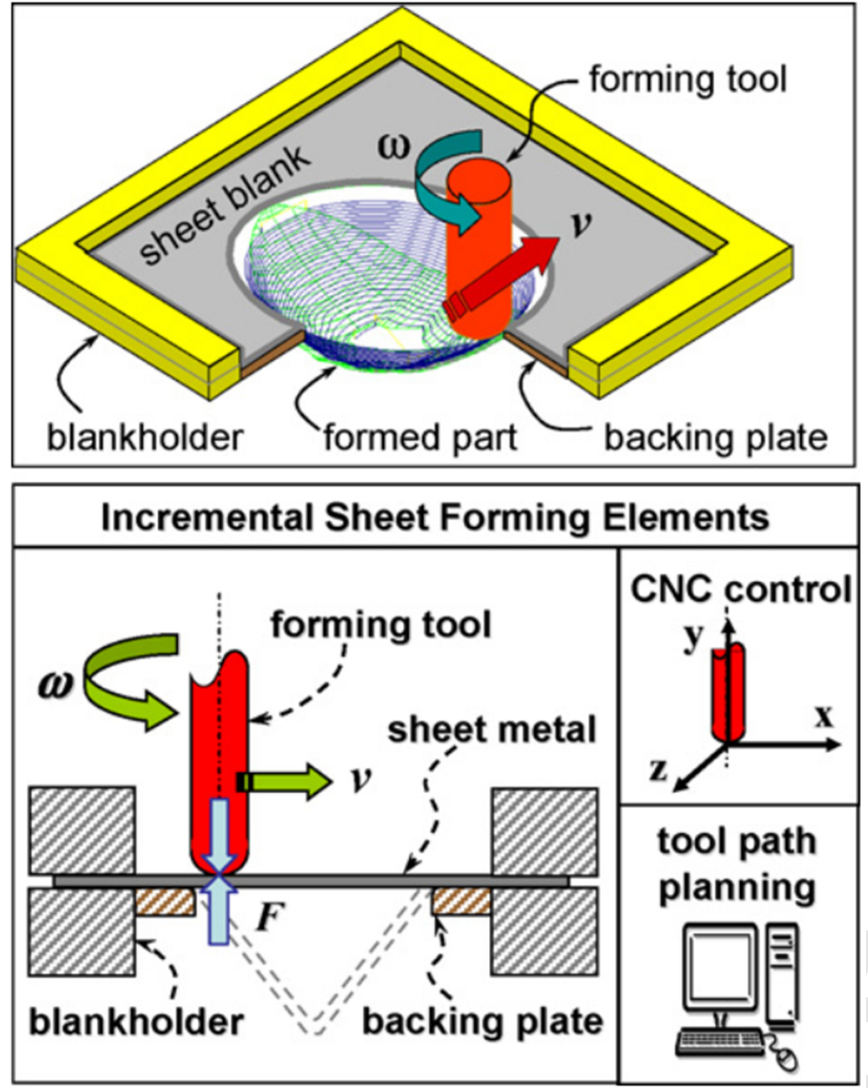

Fig. 1. Single-point incremental sheet forming [4]. force level decrease with material grain size. Shanmuganatan and Kumar [19] used the Central Composite Design (CCD) to investigate the influence of different process parameters on the average thickness, wall angle, and surface roughness of aluminum alloy. Gatea et al. [20] present the influence of process parameters on formability, deformation and failure mechanics, springback, and surface roughness. A review on the effect of process parameters on sheet thickness reduction and mechanical properties, using the response surface methodology, with a Box-Behnken design, is done by Li et al. [21]. Pathak [22] discuss the effects of forming angle, tool diameter, tool velocity (feed rate), spindle speed, vertical pitch, and plastic anisotropy of material on ISF.

Recently researchers focus their attention on the modeling and the numerical simulation in incremental forming to study the influence of process parameters on the geometrical precision and mechanical properties [23,24]. It is found that for complex parts, the excessive thinning produced at larger deformation affects the design requirements and impedes the industrial application of ISF [25]. Also, springback is the major source of error that affects geometrical accuracy. It is used as an evaluation index to examine the precision and quality of the forming parts during the incremental forming process before industrial applications [26]. For these reasons, the definition of the optimal process parameters set, which can control geometrical quality and improve thickness distribution, is a critical issue. Although substantial research works discuss the profiles geometry and thickness distribution,

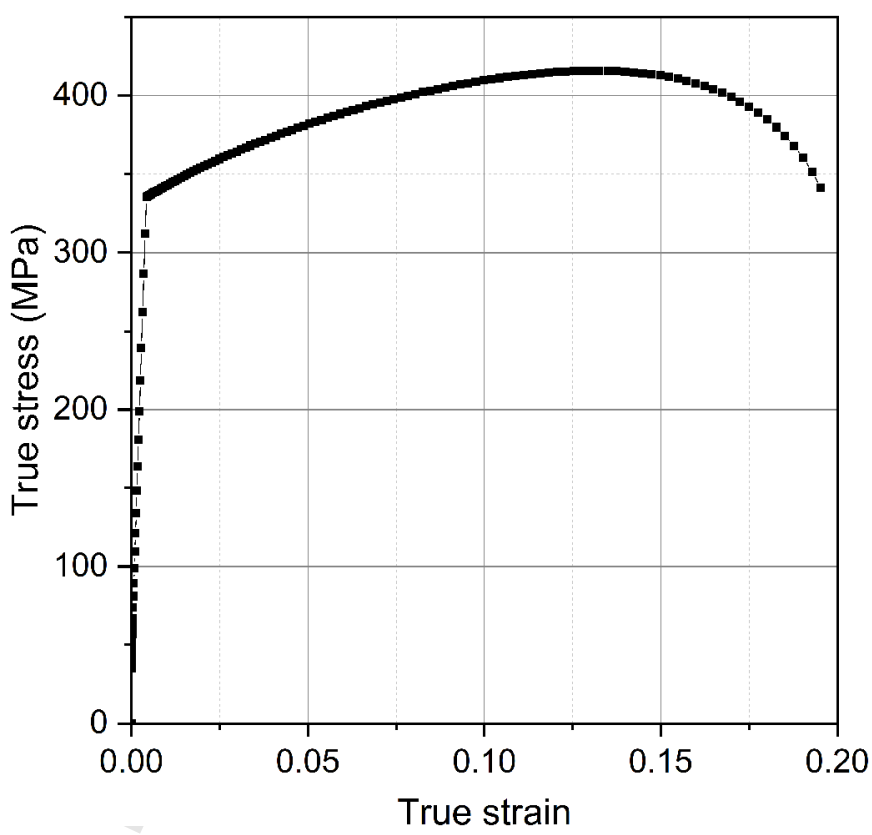

Fig. 2. Stress-Strain curve from a tensile test.

the coupled effect of process parameters on thickness reduction has little attention. Furthermore, the analysis and prediction of the springback phenomenon of the sheet material after the ISF process have not received sufficient attention yet. Therefore, the present work aims to investigate the profile geometry and thickness evolution of a truncated pyramid. The numerical results are assessed by comparison to the experiments. Also, a sensitivity study of the effects of the most relevant process parameters (tool diameter, forming angle, sheet thickness, and tool path) on thickness reduction and springback of the truncated pyramid using numerical response surface methodology is conducted. Finally, a numerical study of damage evolution during the SPIF process at different forming angles is carried out.

\section{Material and methods}

\subsection{Material}

$2 \mathrm{~mm}$ thick square $\left(140 \times 140 \mathrm{~mm}^{2}\right)$ aluminum sheets A2024-T351 are deformed incrementally by the SPIF process. A series of uniaxial tensile tests are conducted according to the ASTM-E8 standard on flat specimens in three orientations $\left(0^{\circ}, 45^{\circ}\right.$, and $\left.90^{\circ}\right)$ relative to the rolling direction at a rate of $2 \mathrm{~mm} / \mathrm{min}$ using a universal testing machine. The obtained stress-strain curve is presented in Figure 2. The main mechanical properties and chemical composition are summarized in Tables 1 and 2.

\subsection{Experimental device and forming strategies}

An experimental device consists of a fixed base and a blank holder clamped on a CNC milling machine as shown in Figure 3a. The device is used to fix the metal sheet during the movement of the forming tool as shown in Figure 3b. 
Table 1. Main mechanical properties of Aluminum alloy A2024-T351.

\begin{tabular}{ll}
\hline Density $\left(\mathrm{kg} / \mathrm{m}^{3}\right)$ & 2780 \\
\hline Young modulus $(\mathrm{GPa})$ & 73.1 \\
Yield stress (MPa) & 345 \\
Poisson ratio & 0.33 \\
Hardness (HV) & 137 \\
\hline
\end{tabular}

Table 2. Chemical composition of Aluminum alloy A2024-T351.

\begin{tabular}{llllllll}
\hline Element & $\mathrm{Al}$ & $\mathrm{Cu}$ & $\mathrm{Mn}$ & $\mathrm{Fe}$ & $\mathrm{Si}$ & $\mathrm{Mg}$ & Other \\
\hline Composition (\%) & 92.25 & 4.4 & 0.6 & 0.5 & 0.5 & 1.5 & 0.25 \\
\hline
\end{tabular}
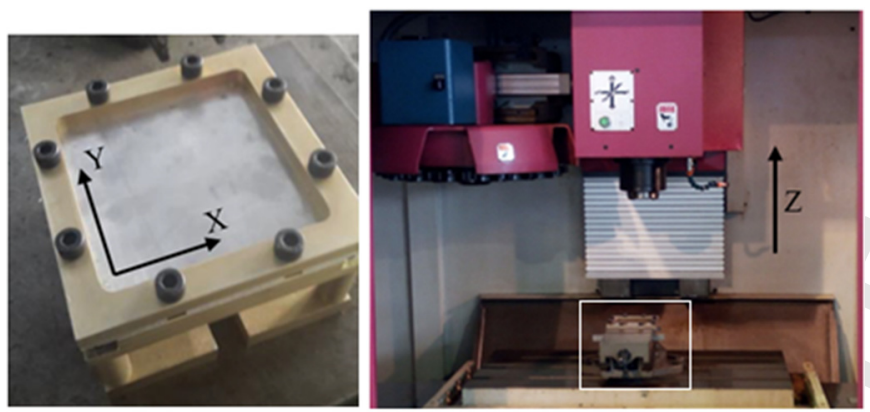

(a)

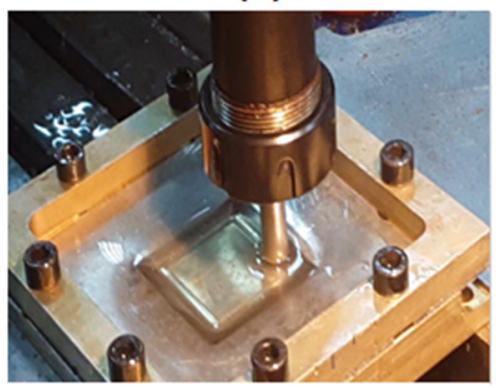

(b)

Fig. 3. (a) Experimental device clamped on a CNC machine; (b) tooling system.

Tools with hemispherical geometries ends of different diameters housed in the CNC machine spindle are used for the forming process. Tool paths are generated with a Computer-Aided Manufacturing (CAM) integrated environment package. During the forming operation, the tool moves in the vertical direction $\mathrm{Z}$ while the sheet moves simultaneously in the $\mathrm{X}, \mathrm{Y}$ directions with the machine table. In order to reduce friction between the tool and the workpiece, mineral oil is used as a lubricant.

The blank holder with a $50 \times 50 \mathrm{~mm}^{2}$ square cavity with a $5 \mathrm{~mm}$ rounding radius is used to avoid sheet tearing. The main SPIF process parameters are given in Table 3.

To investigate the SPIF process, a tool with a pyramidal shape and a forming angle $\alpha$ is used. The shape geometry definition is illustrated in Figure 4.
Table 3. SPIF process parameters and geometry.

\begin{tabular}{ll}
\hline Tool diameter & $10 \mathrm{~mm}$ \\
\hline Tool depth step & $0.1 \mathrm{~mm}$ \\
Spindle speed & $1000 \mathrm{rpm}$ \\
Feed rate & $1500 \mathrm{~mm} / \mathrm{min}$ \\
Major base & $50 \mathrm{~mm}$ \\
Height & $10 \mathrm{~mm}$ \\
Forming angle & $45^{\circ}$ \\
\hline
\end{tabular}

For the tool path selection, two cases are considered: a constant Z-level (discontinuous path in Fig. 5a) and a helical path (continuous path in Fig. 5b).

To compare the obtained results, numerical simulations are performed with the same set of experimental parameters (forming device, tools, and forming strategies).

\subsection{Numerical methods}

Numerical simulations based on the finite element method are very useful for the development of the SPIF. Thibaud et al. [27], Dejardin et al. [28], and Henrard et al. [29-31] propose optimal approaches for numerical modeling to correctly predict the forming process. A finite element analysis is used to simulate the SPIF process. Therefore, the prediction of sheet thickness evolution and geometrical profile of a truncated pyramid is obtained. The GursonTvergaard- Needleman (GTN) damage model is chosen for the prediction of the material damage evolution [32-36]. The yield surface is given by equation (1):

$\phi=\left(\frac{\sigma_{e q v}}{\sigma_{y}}\right)^{2}+2 q_{1} f^{*} \cosh \left(-3 q_{2} \frac{\sigma_{m}}{2 \sigma_{y}}\right)-\left(1+\left(q_{1} f^{*}\right)^{2}\right)=0$

where $\sigma_{e q v}$ is the von Mises equivalent stress, initially equal to $\sigma_{y}$ (initial yield stress), $\sigma_{m}$ represents the hydrostatic stress, and $\left(q_{1}, q_{2}\right)$ are the Tvergaard's coefficients.

The function $f(f)$ defines the void volume fraction in the GTN model and is defined by:

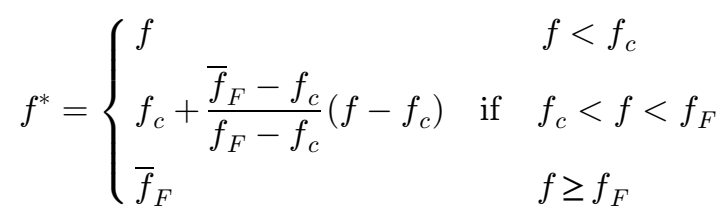

where $f$ the void volume fraction, initially equal to $f_{0}, f_{c}$ the critical void volume fraction, $f_{F}$ the void volume fraction at fracture, and $\bar{f}_{F}=1 / q_{1}$.

The void volume fraction is given by equation (3).

$$
\dot{f}=(1-f) \operatorname{tr}\left(\dot{\varepsilon}^{P}\right)+\frac{f_{N}}{S_{N} \sqrt{\pi}} \exp \left[-\frac{1}{2}\left(\frac{\bar{\varepsilon}^{P}-\varepsilon_{N}}{S_{N}}\right)^{2}\right] \dot{\bar{\varepsilon}}^{P}
$$




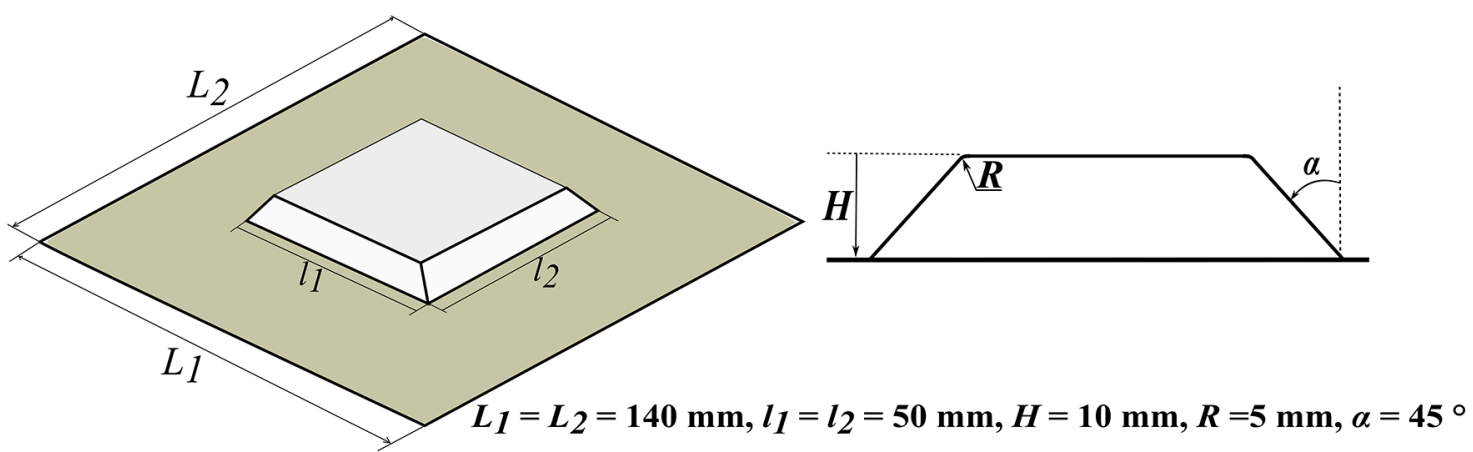

Fig. 4. Geometry definition of the pyramidal shape.

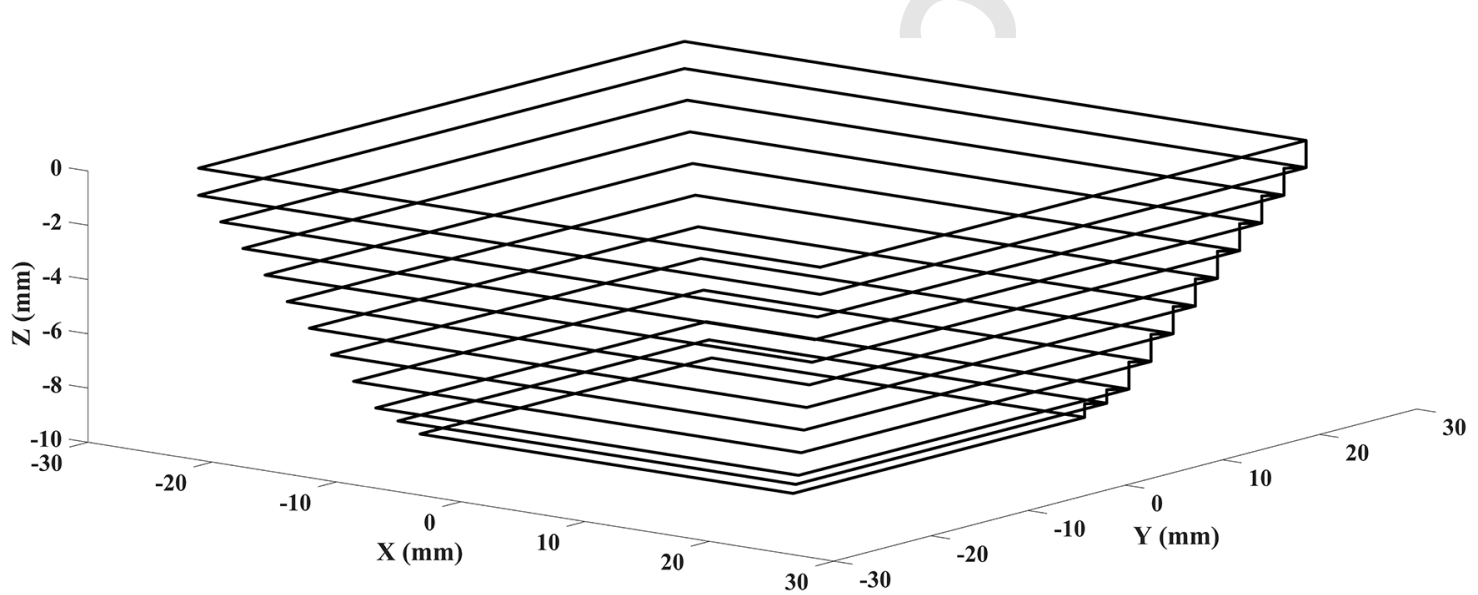

(a)

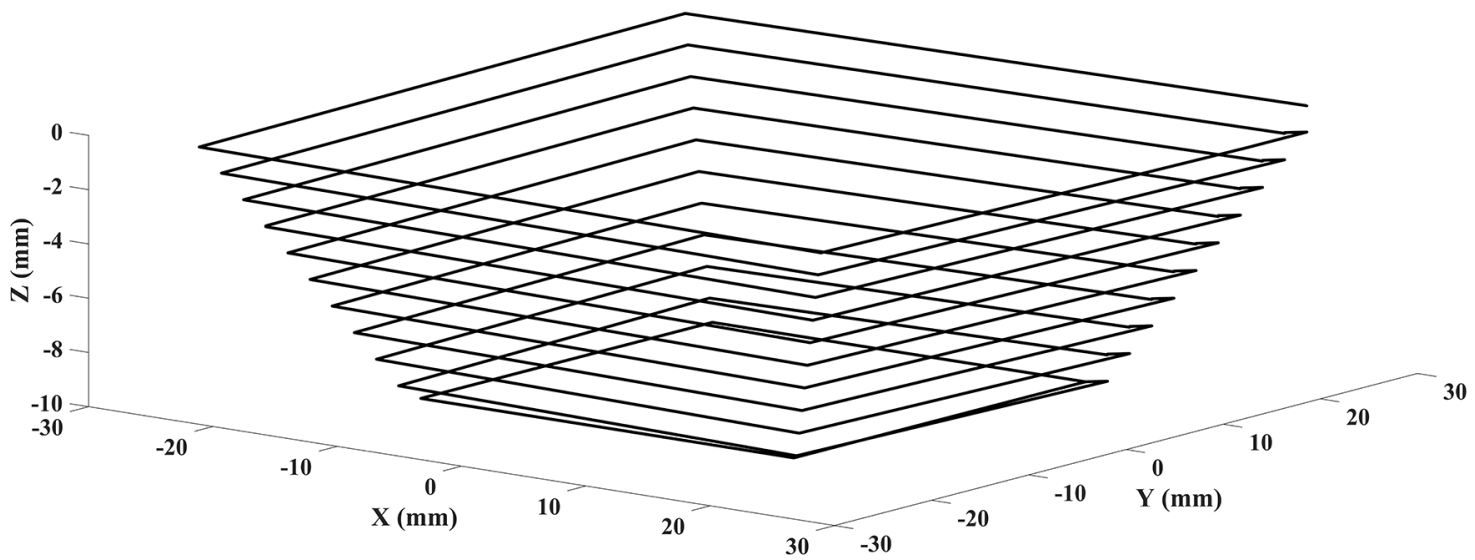

(b)

Fig. 5. Forming strategies: (a) constant Z-level; (b) helical.

where $f_{N}$ is the void volume fraction due to nucleation of new cavities, $\varepsilon_{N}$ the plastic strain at the start of nucleation, $S_{N}$ the standard deviation of the nucleation strain. $\frac{p}{\varepsilon}$ and $\dot{\bar{\varepsilon}}^{p}$ represent respectively the equivalent plastic strain and the equivalent plastic strain rate in the material matrix.

For the plastic flow definition, the Von Mises yield criterion is used. Plastic evolution is based on Voce's isotropic hardening law [37] given by equation (4).

$$
\sigma=\sigma_{y}+Q\left(1-\exp \left(-b \varepsilon^{p}\right)\right)
$$

where $\sigma_{y}$ is the initial yield stress, $Q$ the saturation value of isotropic hardening, and $b$ the hardening exponent.

The GTN model shown in equation (1) has eight variables. The parameters $\left(q_{1}, q_{2}\right)$ are determined using the uniaxial tensile tests. The parameters $f_{0}, f_{c}$ and $f_{F}$ associated with the void growth are obtained by calibration methods. Finally, the three parameters of void nucleation $f_{N}, S_{N}$ and $\varepsilon_{N}$, are derived from metallurgical observation of microcavities [38]. 
Table 4. Identified material parameters of A2024-T351 alloy.

\begin{tabular}{|c|c|c|c|c|c|c|c|c|c|c|}
\hline \multicolumn{3}{|c|}{ Hardening model } & \multicolumn{8}{|c|}{ GTN model } \\
\hline$\sigma_{y}(M P a)$ & $Q(M P a)$ & $b$ & $q_{1}$ & $q_{2}$ & $f_{0}$ & $f_{c}$ & $\varepsilon_{N}$ & $S_{N}$ & $f_{N}$ & $f_{F}$ \\
\hline 345 & 145 & 17.8 & 1.25 & 0.98 & 0.0014 & 0.02 & 0.3 & 0.1 & 0.015 & 0.04 \\
\hline
\end{tabular}

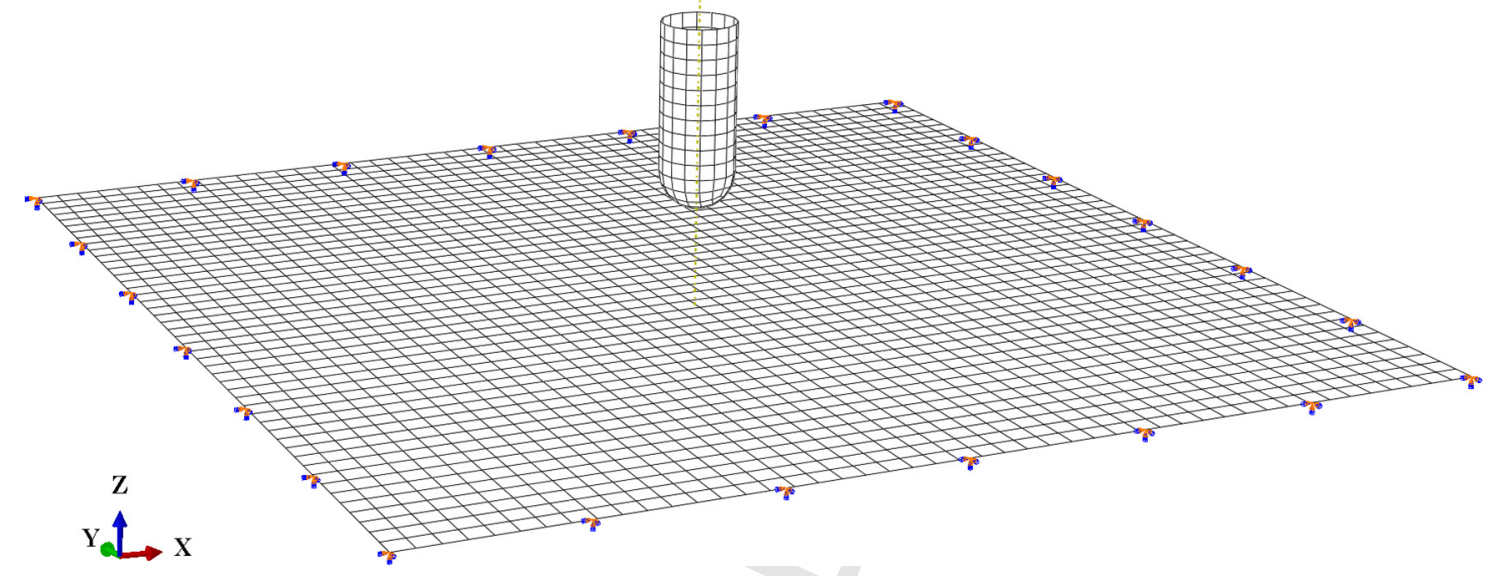

Fig. 6. FE model geometry with boundary conditions.

\subsubsection{Identification of the material parameters}

To identify the GTN model parameters, an inverse method is used. We consider the tensile tests described in Section 2.1. The load-displacement curve from these tests is used to identify the hardening and damage parameters for the A2024-T351 Aluminum alloy.

The adopted inverse method is the Finite Element Updating Method (FEUM) [39]. The FEUM is a mixed numerical-experimental procedure where the difference between a measured response and a calculated one is minimized via an optimization technic by taking the wanted parameters as variables. In the present work, the optimization procedure is based on the LevenbergMarquardt optimization algorithm.

Firstly, for the isotropic hardening model parameters, on the range of small to moderate deformations of the uniaxial tensile test of the considered material, a simple regression of the experimental data with the Voce law defined in equation (4) is used to identify the three associated parameters. Secondly, the hardening parameters obtained in the previous step are then used for the simulation of the tensile test until the final fracture of the specimen. The GTN model damage parameters are identified via the FEUM. The obtained parameters are given in Table 4 . These results are agreeing with those reported in the literature $[36,40]$.

The tool is considered rigid and the corresponding boundary conditions are path-dependent. Coulomb frictional contact behavior is adopted, between the forming tool and the metal sheet with a friction coefficient value equal to $0.05[17,31]$. It is also important to note that the GTN model has undergone several extensions. These models are applied successfully in practical cases [41-46]. In this study, it is chosen to use the model available in Abaqus to optimize computation time.

\subsubsection{Finite element simulation of SPIF}

SPIF process simulations are done with the commercial finite element code Abaqus/Explicit. The metal sheet is meshed with quadrilateral shell elements S4R of 4-nodes with 6 degrees of freedom per node. The R3D 4 element type is selected for the tool. A reduced integration with 5 thickness integration points and a large strain formulation are used. After a mesh convergence study, an element size of $1 \times 1 \mathrm{~mm}$ is found to be appropriate for the discretization of the metal sheet. The whole sheet contains 19600 elements and 19881 nodes.

For boundary conditions, the sheet is clamped around its contour (4 edges) in all 3 directions. Then, the boundary conditions of the tool are related to the defined path during process operation. Finally, the tool path coordinates in $\mathrm{x}, \mathrm{y}$, and $\mathrm{z}$ are linked with the same time instant using three tabular $(\mathrm{t}, \mathrm{x}),(\mathrm{t}, \mathrm{y})$, and $(\mathrm{t}, \mathrm{z})$. Model geometry with boundary conditions are illustrated in Figure 6 .

\section{Results and discussions}

\subsection{Geometrical comparisons}

The obtained results for the 2024 aluminum sheet SPIF study are then presented. For the sake of the finite element simulation assessment, the numerical predictions are compared to experimental results. Figure 7 shows a comparison between experiments and simulations for a constant Z-level strategy. 


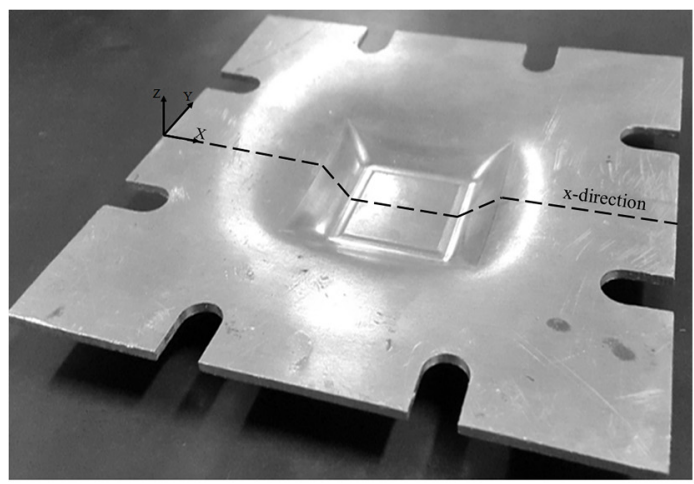

(a)

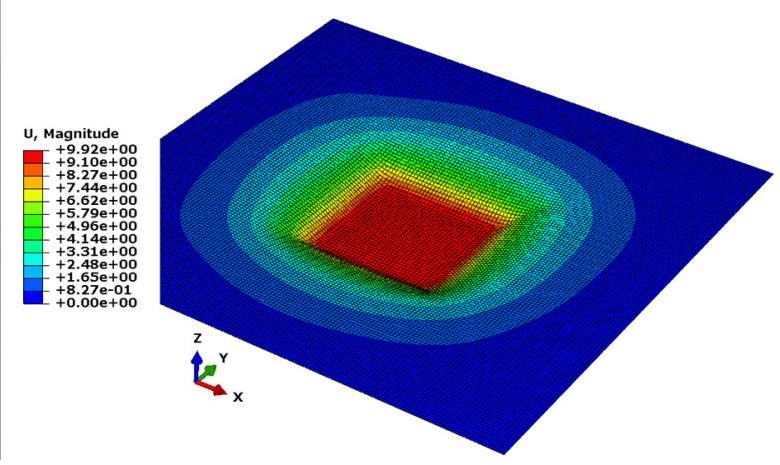

(b)

Fig. 7. Incremental forming operation (a) experimental; (b) numerical.

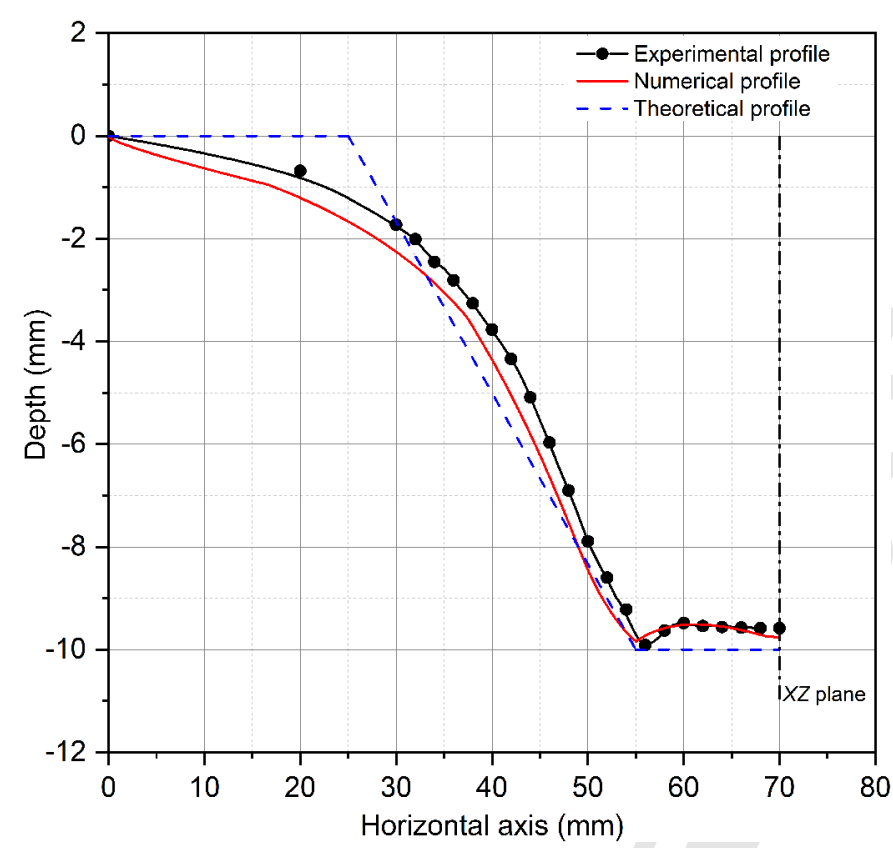

Fig. 8. Comparison of experimental, numerical, and theoretical profiles.

Profile and sheet thickness are measured with metrological tools (Vernier caliper, comparator, and micrometer gauges) in the $\mathrm{XZ}$ plane $(\mathrm{Y}=0)$. The profile is determined as a result of the measurements of the vernier height gauge to find the formed height. The thickness distribution is measured to predict the region where more amount of thinning takes place. For doing this the specimen was cut into two pieces exactly using wire cut EDM. The thickness measurement was conducted in the $\mathrm{x}$-direction (XZ plane) along the midline of the sidewall of the formed pyramid parts. The measurement starts at the part edge and was taken in every predefined point along the cut direction using micrometer gauges and digital vernier caliper. For each point, three measurements are taken and the average value is considered as the measured thickness.
No considerable thickness difference was observed among the two sides of the formed part. Therefore, only one side of the pyramid was selected to take the measurement.

The comparison of the experimental and numerical profiles after the forming operation is presented in Figure 8. It can be seen that the final shape of the experimentally obtained workpiece is correctly predicted by the simulated one. Indeed, the average difference between profiles is less than $4.0 \%$.

Figure 9 gives a comparison between numerical and experimental thicknesses evolution. These thicknesses are sampled along the x-direction (Fig. 7a). A good correlation is found with a maximal relative error of $3.5 \%$. This fact is also supported by previous simulations using the solid-shell element formulation $[47,48]$.

\subsection{Response surface methodology}

The experimental design method is used to study the influence of ISF factors (tool diameter, forming angle, sheet thickness, and the tool path) on the considered responses (variation of thickness and springback) using finiteelement simulations performed with Abaqus/Explicit solver. The prediction of the springback in the framework of an explicit calculation is done in one increment after unloading as proposed in $[49,50]$. The full factorial design for the response variables study is chosen. A set of 16 tests $\left(2^{4}\right)$ is then used. Factors levels are summarized in Table 5.

The maximum depth after springback and minimum thickness results are presented in relative values for better visualization. Thickness reduction and springback effects rates are calculated using the following equations:

$$
\text { Thickness reduction }(\%)=\frac{\mathrm{TH}_{\text {initial }}-\mathrm{TH}_{\text {final }}}{\mathrm{TH}_{\text {initial }}} 100 \%
$$

Spring $\operatorname{back}(\%)=\frac{\text { Depth }_{\text {nominal }}-\text { Depth }_{\text {final }}}{\text { Depth }_{\text {nominal }}} 100 \%$.

Test design and calculated response values are presented in Table 6 . 


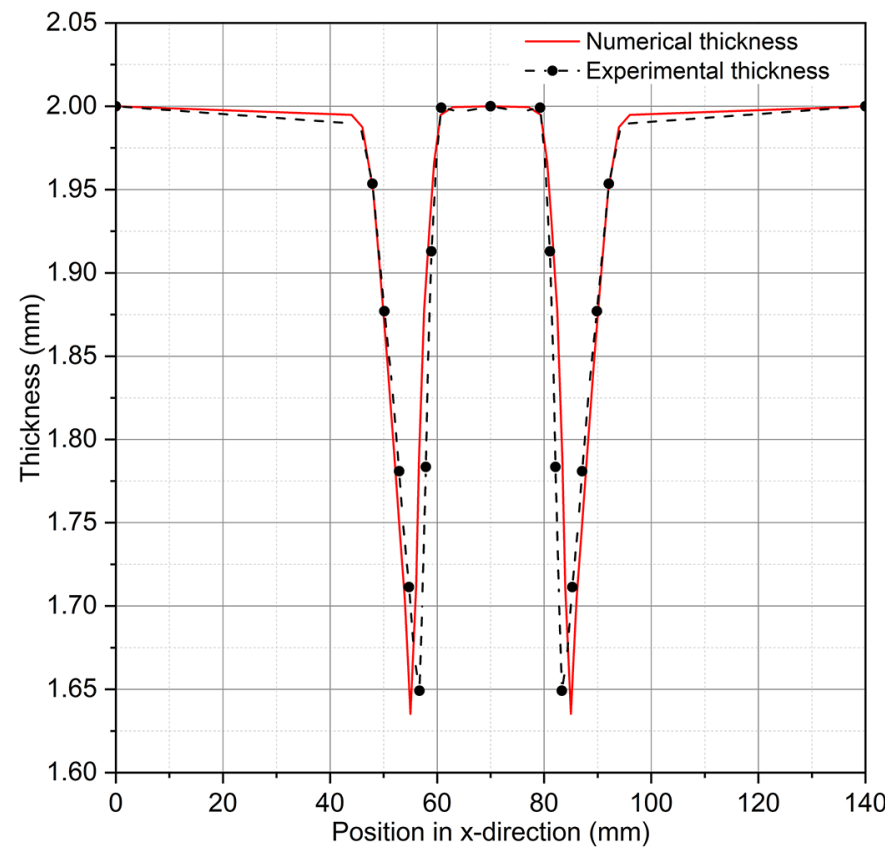

Fig. 9. Numerical and experimental thickness evolution.

A preliminary analysis of the obtained results by the DOE technique [51] has led to the determination of significance parameters levels and their interactions. Results show that the second-order interactions are more visible and significant compared to higher-order ones. Therefore, only second-order combinations are considered for interaction representation. The results are shown in Table 7 and Figure 10.

For the thickness reduction response, Figure 10a shows that the forming angle is the most significant factor, followed by the tool diameter. In this way, thickness reduction increases as the forming angle and the tool diameter increase. Springback response, given in Figure 10b, shows that the forming angle is the most significant factor followed by the tool path, sheet thickness, and tool diameter. The springback response increases as the forming angle, sheet thickness, and tool diameter decrease and as the tool path strategy changes to the helical form. Indeed, we observed that helical form gives more springback than the constant-Z level strategy. This finding is explained by the fact that the helical path increases the continuous local springback which occurs simultaneously with the displacement of the tool due to the angle of displacement of the tool (variable step depth) [26]. Besides, the step depth is constant in the constant-Z level strategy.

Using data from Table 7 and considering a full factorial design, the expressions of the responses function are given for thickness reduction and springback by equations (7) and (8) respectively:

Thickness reduction $(\%)=17.662+0.981 A+3.786 B$

$$
\begin{aligned}
& -0.388 C+0.259 D+0.191 A B+0.364 A C \\
& \quad+0.097 A D-0.481 B C \\
& \quad+0.312 B D-0.224 C D
\end{aligned}
$$

$$
\begin{gathered}
\text { Spring back }(\%)=9.540-0.596 A-3.648 B-0.810 C \\
+1.189 D+0.221 A B-0.029 A C+0.068 A D \\
+0.168 B C-0.059 B D-0.591 C D
\end{gathered}
$$

Figures 11 and 12 show the effect interaction influence of the four input parameters for thickness reduction and springback responses. Effect interaction plots allow the investigation of factor dependence. Two factors are considered dependent when two lines cross each other.

For the thickness reduction, we noticed that the factors are dependent on each other except for the tool diameterforming angle interaction. For springback, no dependence between factors is observed.

The analysis of variance (ANOVA) is adopted to evaluate the influence of each factor on the responses. Parameters influencing the thickness reduction and springback are determined based on a confidence level of $95 \%$. The effect of each factor on the response is considered significant if the probability value (P-value) is less than or equal to 0.05. ANOVA results for thickness reduction and springback are summarized in Tables 8 and 9 , respectively.

The ANOVA results indicate that the forming angle is the most influential factor on thickness reduction with a contribution of $88.59 \%$ followed by the tool diameter with an influence of $5.94 \%$. Taking into account the P-value of 0.05 , it appears that three factors are relevant in the case of springback. These factors are: forming angle, tool path, and sheet thickness with a contribution of $81.99 \%, 8.71 \%$, and $4.04 \%$ respectively. Similar results were observed by $\mathrm{Li}$ et al. [25] and Zhang et al. [26].

\subsection{Analysis of damage evolution}

In this section, we focus on the analysis of the damage evolution as a function of the input parameters of the single-point incremental forming process. The porosity $f$, which is the void volume fraction, represents the damage parameter.

The results of the previous sections show that the forming angle is the most influential factor. Several studies [20-22,25] showed that the forming angle has a significant effect on stress evolution and porosity of the formed material. Based on this latter, several FE simulations in Abaque/Explicit are performed on a SPIF truncated pyramid with different forming angles: $30^{\circ}, 45^{\circ}$, and $60^{\circ}$. These simulations are carried out to analyze porosity evolution in two formed sheet zones: Zone-1 and Zone-2, (Fig. 13). All the pyramids have the same major base of $50 \mathrm{~mm}$ and a height of $10 \mathrm{~mm}$. Process parameters of the numerical model are the same as those mentioned in Section 2.3.1.

Figure 14 shows the isovalues of porosity for the three forming angles over all the integration points (IP). Each integration point is linked to a position in the shell element. The integration point IP-3 is placed in the middle sheet. Then, IP-2 and IP-4 are placed below and above IP-3 respectively. Finally, IP-1 and IP-5 are placed below and above IP-2 and IP-4 respectively. Therefore, IP-5 is near the top sheet surface which is in contact with the tool. In this case, the maximum observed in the corners can be 
Table 5. Factors levels assignment.

\begin{tabular}{llll}
\hline & & \multicolumn{2}{c}{ Factors levels } \\
\cline { 3 - 4 } Factors & Symbols & Low $(-1)$ & High $(+1)$ \\
\hline Tool diameter $(\mathrm{A})$ & $\mathrm{D}(\mathrm{mm})$ & 8 & 14 \\
Forming angle $(\mathrm{B})$ & $\alpha\left(^{\circ}\right)$ & 30 & 45 \\
Sheet thickness $(\mathrm{C})$ & $\mathrm{TH}_{\mathrm{i}}(\mathrm{mm})$ & 1.5 & 2.5 \\
Tool path $(\mathrm{D})$ & $\mathrm{T}_{\mathrm{p}}$ & Constant Z-level & Helical \\
\hline
\end{tabular}

Table 6. Test design and results.

\begin{tabular}{llllllll}
\hline & \multicolumn{3}{c}{ Design of tests } & & \multicolumn{2}{c}{ Test results } \\
\cline { 2 - 4 } Test number & $\mathrm{D}$ & $\alpha$ & $\mathrm{THi}$ & $\mathrm{T}_{\mathrm{p}}$ & & Thickness reduction $(\%)$ & Springback $(\%)$ \\
\hline 1 & -1 & -1 & -1 & -1 & 13.80 & 12.95 \\
2 & +1 & -1 & -1 & -1 & 13.60 & 11.33 \\
3 & -1 & +1 & -1 & -1 & 20.80 & 5.60 \\
4 & +1 & +1 & -1 & -1 & 22.07 & 4.40 \\
5 & -1 & -1 & +1 & -1 & 12.56 & 12.61 \\
6 & +1 & -1 & +1 & -1 & 15.76 & 10.87 \\
7 & -1 & +1 & +1 & -1 & 18.92 & 4.90 \\
8 & +1 & +1 & +1 & -1 & 21.72 & 4.15 \\
9 & -1 & -1 & -1 & +1 & 13.27 & 16.70 \\
10 & +1 & -1 & -1 & +1 & 14.47 & 8.68 \\
11 & -1 & +1 & -1 & +1 & 21.87 & 7.72 \\
12 & +1 & +1 & -1 & +1 & 24.53 & 13.76 \\
13 & -1 & -1 & +1 & +1 & 12.72 & 11.60 \\
14 & +1 & -1 & +1 & +1 & 14.84 & 6.15 \\
15 & -1 & +1 & +1 & +1 & 19.52 & 5.80 \\
16 & +1 & +1 & +1 & +1 & 22.16 & \\
\hline
\end{tabular}

Table 7. Effects and interaction of factors.

\begin{tabular}{llll}
\hline Effect & & Thickness reduction (\%) & Springback (\%) \\
\hline Average values & & 17.662 & 9.540 \\
Tool diameter & $(\mathrm{A})$ & 0.981 & -0.596 \\
Forming angle & (B) & 3.786 & -3.648 \\
Sheet thickness & (C) & -0.388 & -0.810 \\
Tool path & (D) & 0.259 & 1.189 \\
Interaction & $(\mathrm{A}-\mathrm{B})$ & 0.191 & 0.221 \\
Interaction & $(\mathrm{A}-\mathrm{C})$ & 0.364 & -0.029 \\
Interaction & $(\mathrm{A}-\mathrm{D})$ & 0.097 & 0.068 \\
Interaction & $(\mathrm{B}-\mathrm{C})$ & -0.481 & 0.168 \\
Interaction & (B-D) & 0.312 & -0.059 \\
Interaction & $(\mathrm{C}-\mathrm{D})$ & -0.224 & -0.591 \\
\hline
\end{tabular}

related to contact effects. This could be explained by the fact that the sudden change in the direction of loading occurring at the corners causes a discontinuity of trajectory and thus accentuates the contact forces. A maximum value of the effective porosity at the top right corner is observed in Figure 14. This value is due to the starting point of the trajectory of the forming tool, the contact starts in the same corner for each case $\left(30^{\circ}, 45^{\circ}\right.$, and $\left.60^{\circ}\right)$ with penetration in Z-direction and then a displacement in the XY plane. The evolution of void volume fraction is 


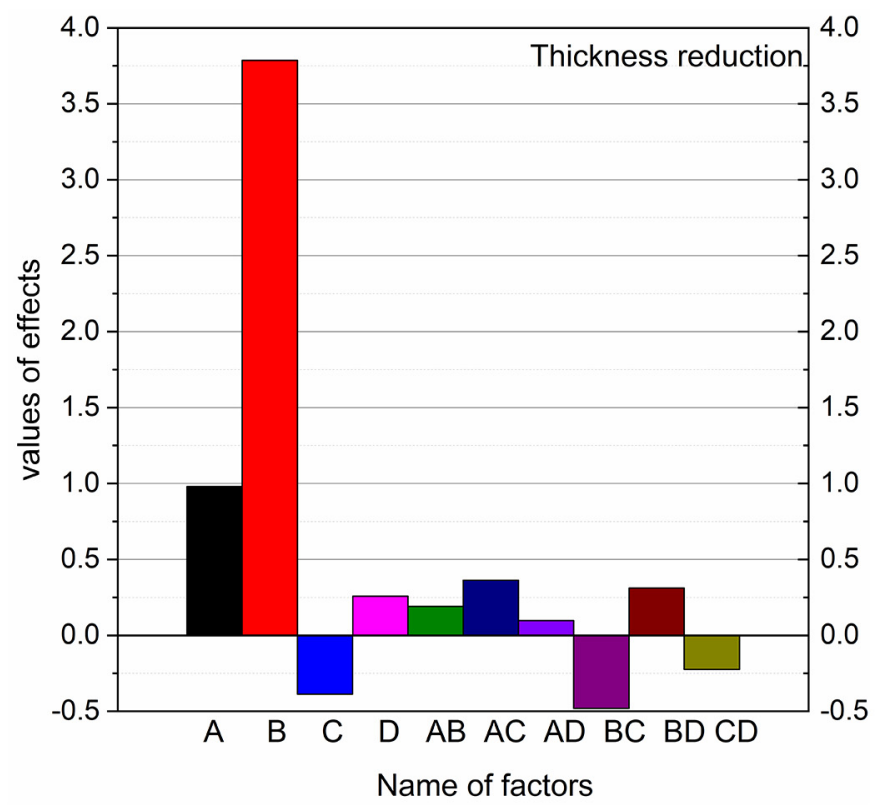

(a)

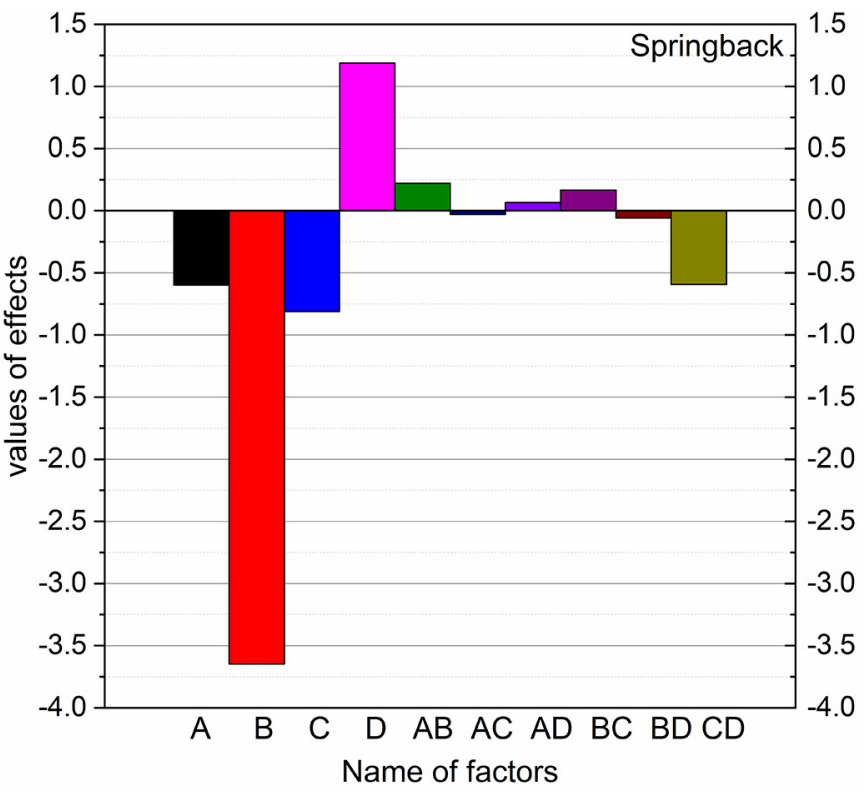

(b)

Fig. 10. Effects and interaction diagrams of factors: (a) thickness reduction; (b) springback.

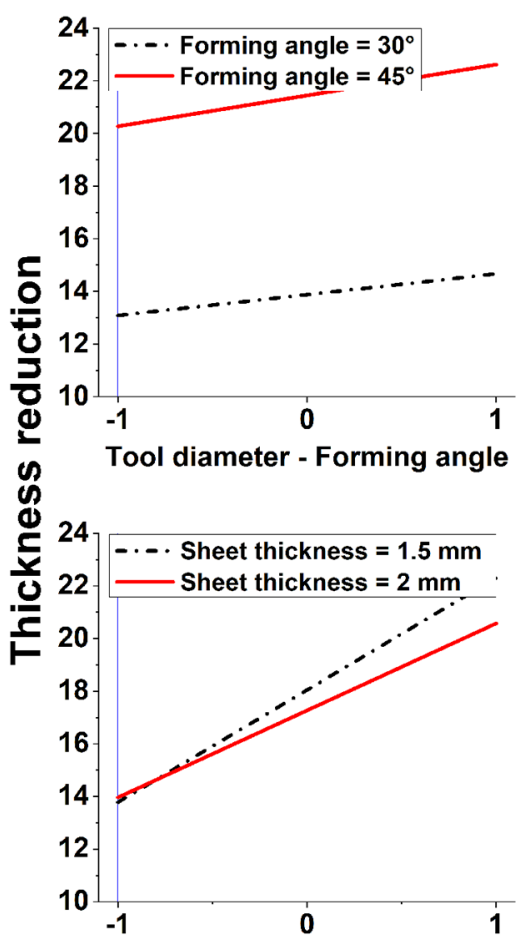

Forming angle - Sheet thickness

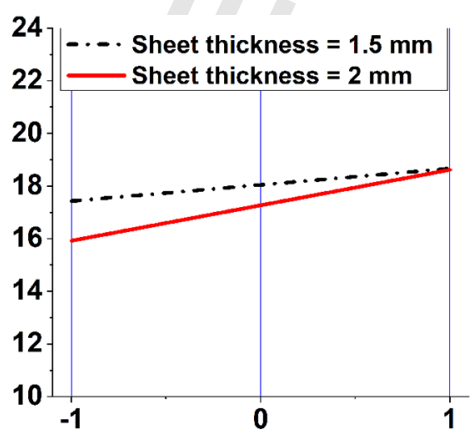

Tool diameter - Sheet thickness

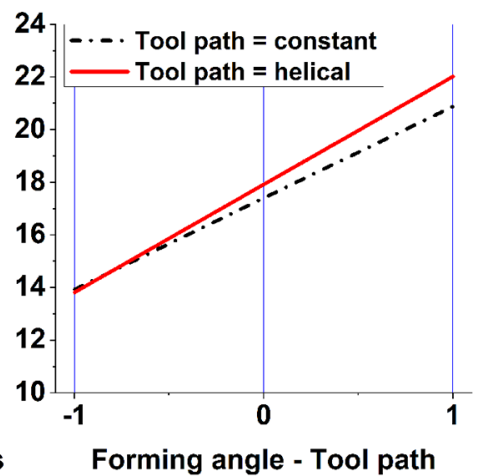

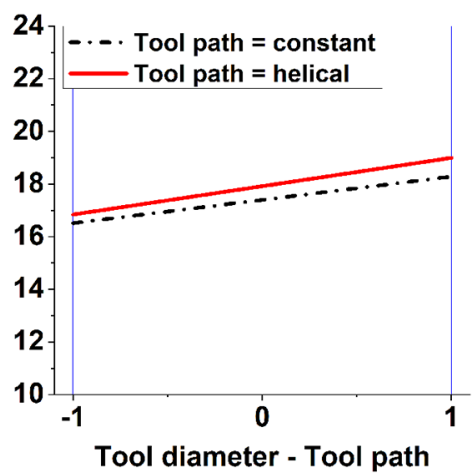

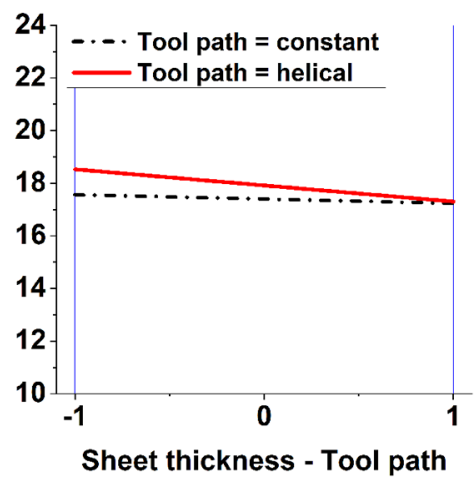

Fig. 11. Interaction plot for thickness reduction.

plotted versus the average equivalent plastic strain in each zone for different angles in two selected zones (Zone-1 and Zone-2) defined in Figures 15 and 16.

We define an average porosity $f$ on a set of carefully selected elements so that we can follow its evolution during incremental forming. Therefore, we adopt the definition, inspired by the definition of the homogenized average stress, below.

$$
f=\frac{\sum f_{\text {ele }, i} V_{\text {ele }, i}}{\sum V_{\text {ele }, i}}
$$




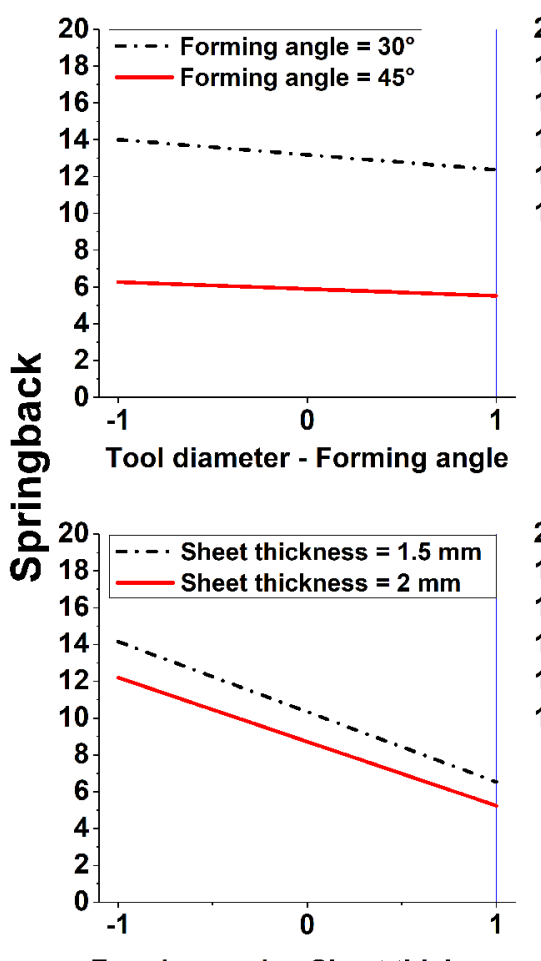

Forming angle - Sheet thickness

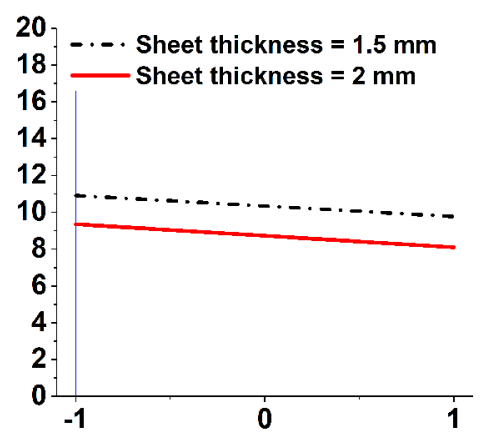

Tool diameter - Sheet thickness

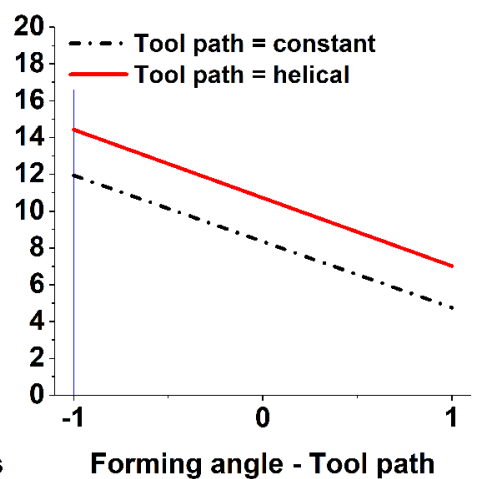

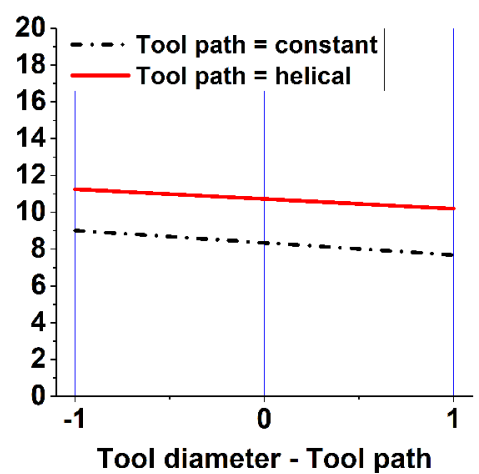

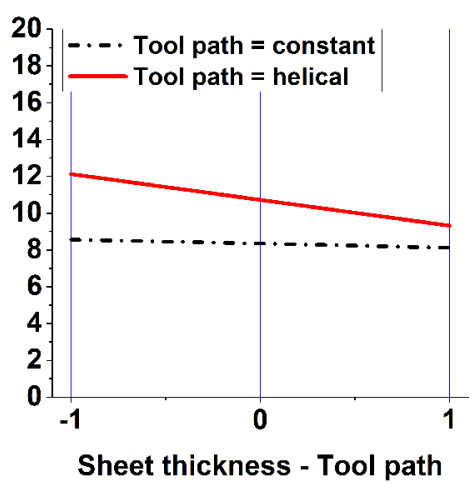

Fig. 12. Interaction plot for springback.

where $i=1,2$ represents zone- 1 or zone- 2 . $V_{\text {ele }}$ and $f_{\text {ele }}$ are respectively the volume and void volume fraction of each element in the respective zones; $f$ is the void volume fraction in each zone (a sectioned of finite elements group). The results are reported in Table 10 .

In Figures 15 and 16, it can be observed that the damage parameter has an abrupt evolution from $5 \%$ of the equivalent plastic strain. For Zone-1, which concerns the loading at the straight side of the pyramid shape, porosity evolution is almost similar for the three forming angles with a maximum value $f=0.01031$ corresponding to the $60^{\circ}$ angle (Fig. 15).

For Zone-2, which represents the pyramid corner, porosity increases with the change of the forming angle with a clear evolution of the volume fraction between the three angles. It is also found that the porosity in zone- 1 is lower than in zone-2. This is because a pyramid corner leads to a higher deformation than a straight side. Therefore, the results reveal that the porosity evolution is sensitive to the forming angle parameter and agree with those reported by Arfa et al. [23] and Junchoa et al. [52]. This variation causes a greater level of damage represented by a rapid evolution of the void volume fraction. These results are confirmed with porosity calculations using equation (9) and summarized in Table 10.

\section{Conclusions and future work}

The present work presents a numerical-experimental study of the influence of single-point incremental forming process parameters (tool diameter, forming angle, sheet thickness, and tool path) on the thickness reduction and springback levels of a truncated pyramid form.

Average sheet thickness and geometrical profile are determined after a set of experimental SPIF testing campaigns. A finite element model (FEM) is developed using the commercial software Abaqus to simulate the SPIF process. The model behavior of the aluminum alloy (A2024-T351) sheet is assumed elastic-plastic with isotropic hardening.

Numerical results are found to be in good agreement with the experimental measurements. The overall profile geometry and thickness variation are close to the real form with a maximum deviation of $4.0 \%$.

Once the finite element model of the SPIF is validated, a full factorial design of 16 experiments provided by response surface methodology is carried out to assess both the single and interactive influence of the considered parameters on the selected responses during the pyramid forming process. Results show that the forming angle is the most influential factor. When it increases, thickness reduction increase, and the springback decrease.

Three truncated pyramids with different forming angles $\left(30^{\circ}, 45^{\circ}\right.$, and $\left.60^{\circ}\right)$ are simulated to assess the effect of the forming angle on damage evolution. The void volume fraction value is taken as an indicator of damage evolution and it is demonstrated that it is sensitive to the forming angle.

Some suggestions for future investigation are provided. The influence of material properties, lubricant, and operating conditions such as feed and spindle rates will be investigated. Moreover, the interaction between metal sheet, tool and process parameters has to be considered. Finally, tool deflection during the ISF process needs to be incorporated. 
Table 8. ANOVA values for thickness reduction.

\begin{tabular}{lllllll}
\hline Source & Sum of squares & Degrees of freedom & Mean square & F Value & p-value & Contribution \% \\
\cline { 5 - 6 } & & & & & Prob > F & \\
\hline Model & 258.76 & 14 & 18.48 & 341.92 & 0.0424 & \\
A & 15.39 & 1 & 15.39 & 284.63 & 0.0377 & $\mathbf{5 . 9 4}$ \\
B & 229.3 & 1 & 229.3 & 4241.79 & 0.0098 & $\mathbf{8 8 . 5 9}$ \\
C & 2.41 & 1 & 2.41 & 44.59 & 0.0946 & 0.93 \\
D & 1.08 & 1 & 1.08 & 19.91 & 0.1403 & 0.42 \\
AB & 0.58 & 1 & 0.58 & 10.76 & 0.1884 & 0.22 \\
AC & 2.12 & 1 & 2.12 & 39.3 & 0.1007 & 0.82 \\
AD & 0.15 & 1 & 0.15 & 2.78 & 0.344 & 0.058 \\
BC & 3.7 & 1 & 3.7 & 68.37 & 0.0766 & 1.43 \\
BD & 1.56 & 1 & 1.56 & 28.79 & 0.1173 & 0.6 \\
CD & 0.81 & 1 & 0.81 & 14.9 & 0.1614 & 0.31 \\
ABC & 0.49 & 1 & 0.49 & 9.13 & 0.2035 & 0.19 \\
ABD & 0.052 & 1 & 0.052 & 0.96 & 0.5069 & 0.02 \\
ACD & 1.02 & 1 & 1.02 & 18.78 & 0.1444 & 0.39 \\
BCD & 0.12 & 1 & 0.12 & 2.23 & 0.3754 & 0.047 \\
Residual & 0.054 & 1 & 0.054 & & & \\
Cor total & 258.82 & 15 & & & & 100 \\
\hline
\end{tabular}

Table 9. ANOVA values for springback.

\begin{tabular}{|c|c|c|c|c|c|c|}
\hline \multirow[t]{2}{*}{ Source } & \multirow[t]{2}{*}{ Sum of squares } & \multirow{2}{*}{ Degrees of freedom } & \multirow[t]{2}{*}{ Mean square } & \multirow[t]{2}{*}{$\mathrm{F}$ value } & \multirow{2}{*}{$\begin{array}{l}\text { p-value } \\
\text { Prob }>\text { F }\end{array}$} & \multirow[t]{2}{*}{ Contribution $\%$} \\
\hline & & & & & & \\
\hline Model & 259.56 & 14 & 18.54 & 350.47 & 0.0418 & \\
\hline $\mathrm{A}$ & 5.69 & 1 & 5.69 & 107.53 & 0.0612 & 2.19 \\
\hline B & 212.87 & 1 & 212.87 & 4023.97 & 0.01 & 81.99 \\
\hline $\mathrm{C}$ & 10.5 & 1 & 10.5 & 198.44 & 0.0451 & 4.04 \\
\hline $\mathrm{D}$ & 22.61 & 1 & 22.61 & 427.41 & 0.0308 & 8.71 \\
\hline $\mathrm{AB}$ & 0.78 & 1 & 0.78 & 14.81 & 0.1619 & 0.3 \\
\hline $\mathrm{AC}$ & 0.013 & 1 & 0.013 & 0.25 & 0.7048 & $5.09 \mathrm{E}-03$ \\
\hline $\mathrm{AD}$ & 0.073 & 1 & 0.073 & 1.38 & 0.4492 & 0.028 \\
\hline $\mathrm{BC}$ & 0.45 & 1 & 0.45 & 8.49 & 0.2105 & 0.17 \\
\hline $\mathrm{BD}$ & 0.055 & 1 & 0.055 & 1.04 & 0.4932 & 0.021 \\
\hline $\mathrm{CD}$ & 5.59 & 1 & 5.59 & 105.73 & 0.0617 & 2.15 \\
\hline $\mathrm{ABC}$ & 0.27 & 1 & 0.27 & 5.01 & 0.2674 & 0.1 \\
\hline $\mathrm{ABD}$ & 0.032 & 1 & 0.032 & 0.61 & 0.5773 & 0.012 \\
\hline $\mathrm{ACD}$ & 0.078 & 1 & 0.078 & 1.48 & 0.4378 & 0.03 \\
\hline $\mathrm{BCD}$ & 0.56 & 1 & 0.56 & 10.49 & 0.1906 & 0.21 \\
\hline Residual & 0.053 & 1 & 0.053 & & & \\
\hline Cor total & 259.61 & 15 & & & & 100 \\
\hline
\end{tabular}




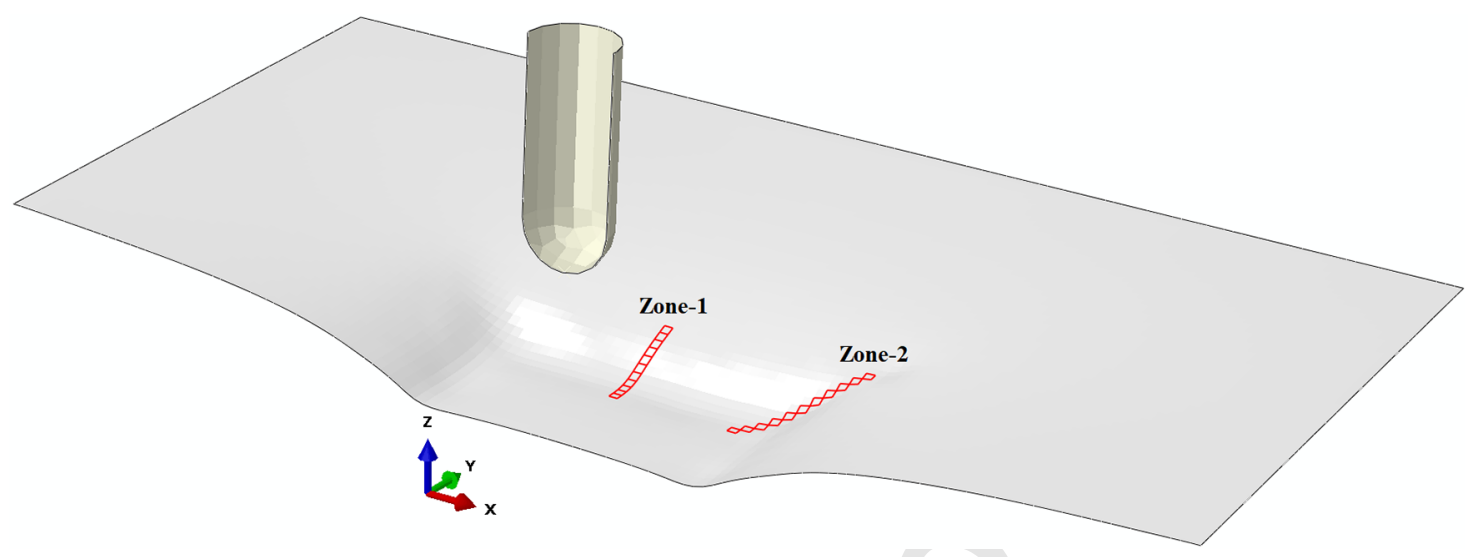

Fig. 13. Damage analysis zones.
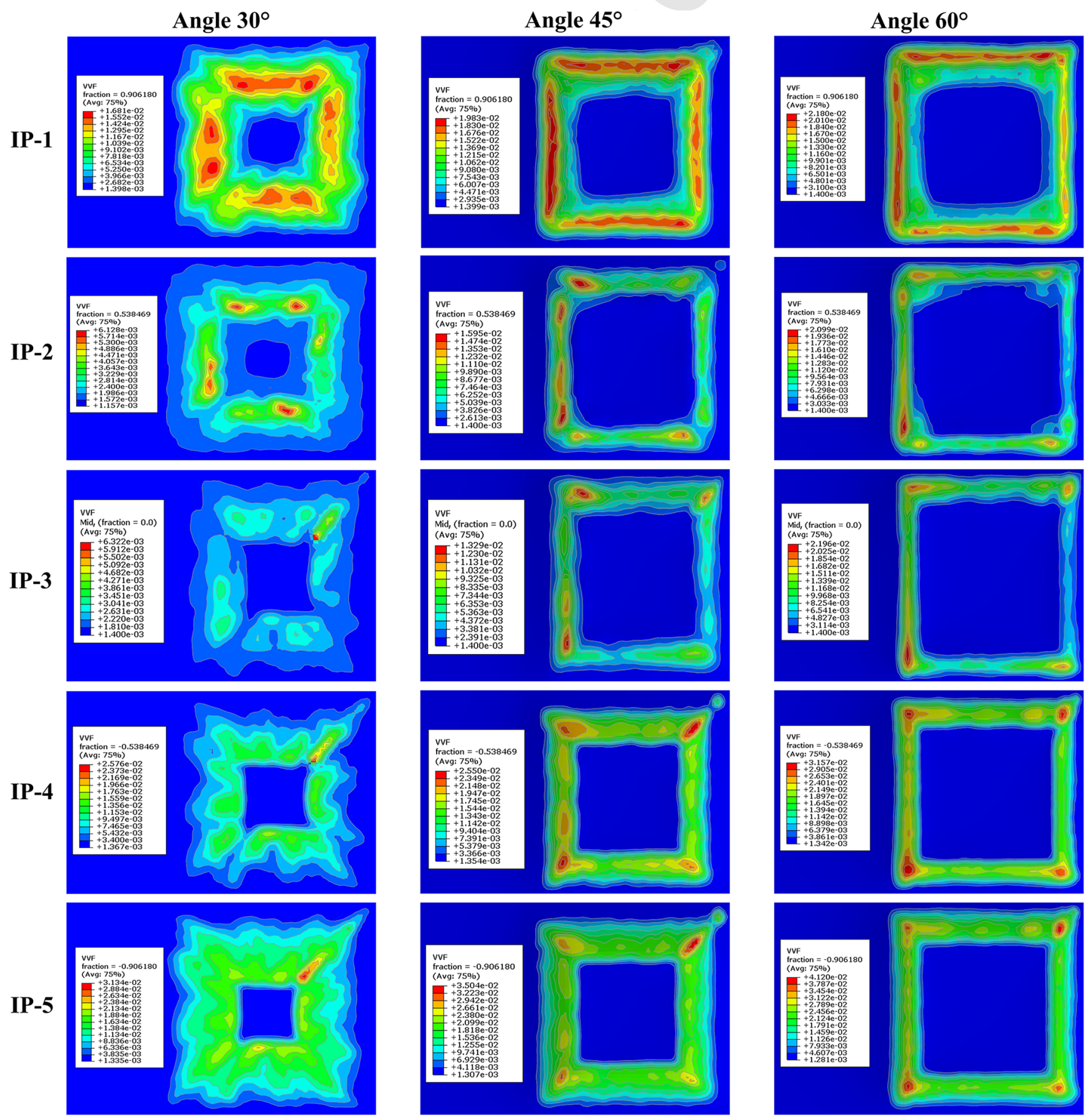

Fig. 14. Isovalues of effective porosity for the SPIF test simulation for $30^{\circ}, 45^{\circ}$, and $60^{\circ}$ over the five integration points considered in all the simulations (IP). 


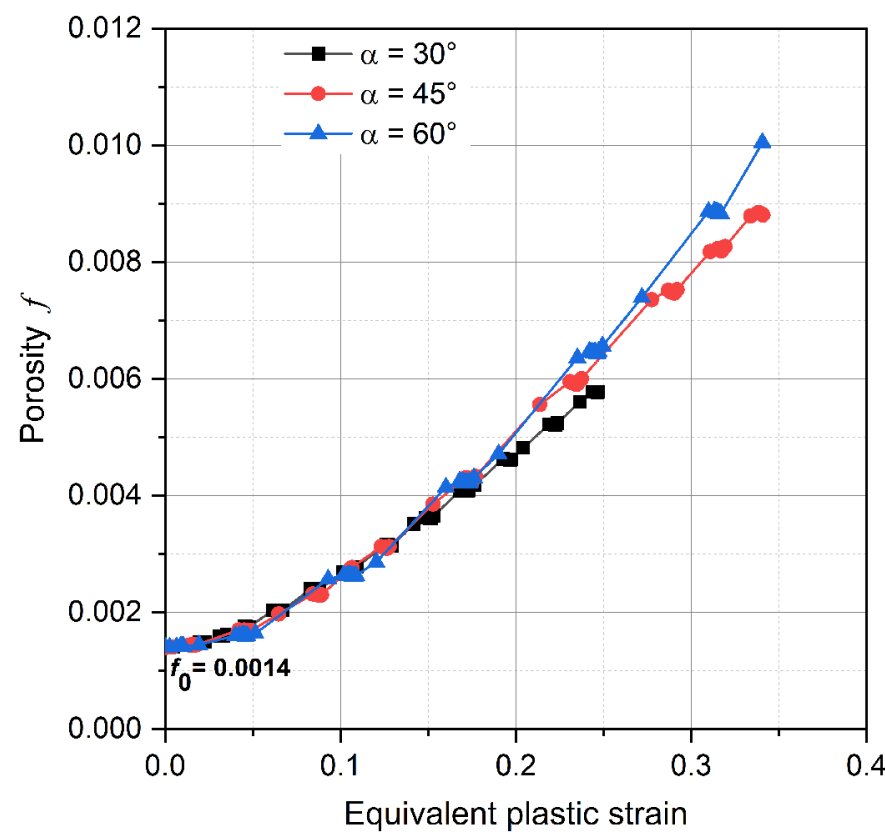

Fig. 15. Porosity evolution in Zone-1 of the sheet.

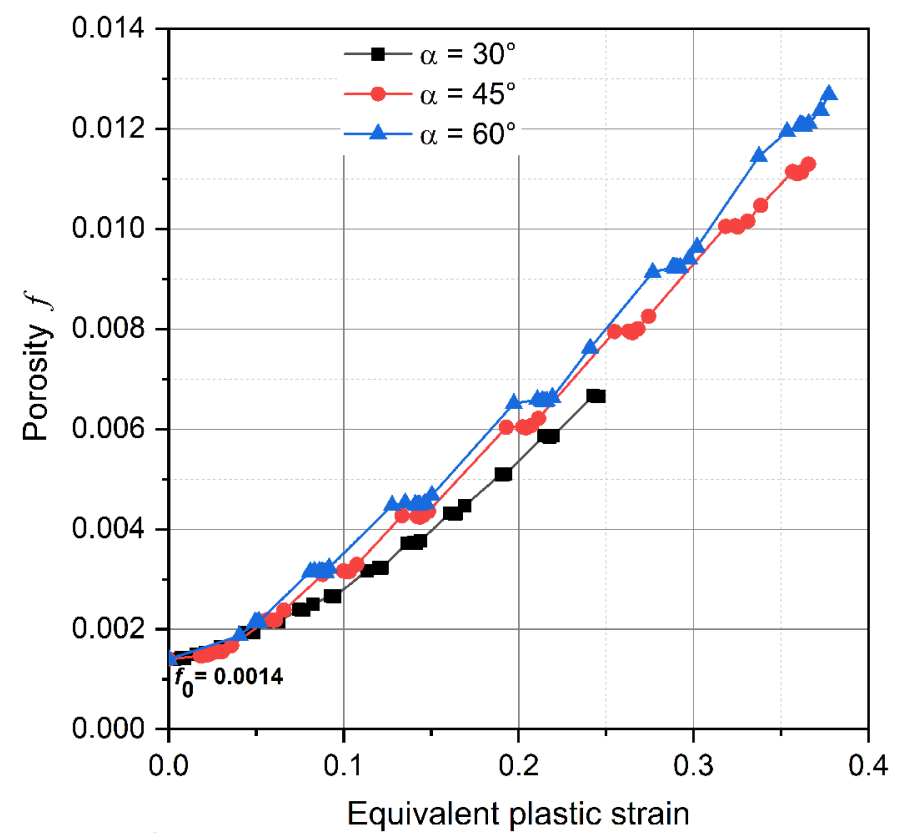

Fig. 16. Porosity evolution in Zone-2 of the sheet.

Table 10. Void volume fraction for the different forming angles.

\begin{tabular}{llll}
\hline \multirow{3}{*}{ Forming angle } & & \multicolumn{2}{c}{ Void volume fraction $f$} \\
\cline { 2 - 3 } & Integration points (IP) & Zone-1 & 0.00611 \\
$30^{\circ}$ & IP-1 & 0.00893 & 0.00239 \\
& IP-2 & 0.00202 & 0.00303 \\
& IP-3 & 0.00212 & 0.01111 \\
& IP-4 & 0.00651 & 0.00616 \\
IP-5 & Average value & 0.00894 & $\mathbf{0 . 0 0 5 7 7}$ \\
IP-1 & $\mathbf{0 . 0 0 5 7 0}$ & 0.02289 \\
$45^{\circ}$ & IP-2 & 0.01427 & 0.01712 \\
& IP-3 & 0.01024 & 0.00662 \\
& IP-4 & 0.00383 & 0.00327 \\
& IP-5 & 0.00444 & 0.00941 \\
$60^{\circ}$ & Average value & 0.01128 & $\mathbf{0 . 0 1 1 8 7}$ \\
& IP-1 & $\mathbf{0 . 0 0 8 8 1}$ & 0.02191 \\
& IP-2 & 0.01690 & 0.01553 \\
& IP-3 & 0.01241 & 0.00789 \\
& IP-4 & 0.00556 & 0.00600 \\
& IP-5 & 0.00536 & 0.01200 \\
& Average value & 0.01134 & $\mathbf{0 . 0 1 2 6 7}$ \\
\hline
\end{tabular}

*Average values are the mean over the five integration points for each angle.

\section{References}

1. E. Hagan, J. Jeswiet, A review of conventional and modern single-point sheet metal forming methods, Proc. Inst. Mech. Eng. Part B J. Eng. Manuf. 217, 213-225 (2003)
2. J. Jeswiet, F. Micari, G. Hirt, A. Bramley, J. Duflou, J. Allwood, Asymmetric single point incremental forming of sheet metal, CIRP Ann. 54, 88-114 (2005)

3. A. Petek, G. Gantar, T. Pepelnjak, K. Kuzman, Economical and ecological aspects of single point incremental forming 
versus deep drawing technology, Key Eng. Mater. 344, 931-938 (2007)

4. J. Jeswiet, M. Geiger, U. Engel, M. Kleiner, M. Schikorra, J. Duflou, R. Neugebauer, P. Bariani, S. Bruschi, Metal forming progress since2000, CIRP J. Manuf. Sci. Technol. 1, $2-17(2008)$

5. W.C. Emmens, G. Sebastiani, A.H. van den Boogaard, The technology of incremental sheet forming - a brief review of the history, J. Mater. Process. Technol. 210, 981-997 (2010)

6. Y. Li, X. Chen, Z. Liu, J. Sun, F. Li, J. Li, G. Zhao, A review on the recent development of incremental sheet-forming process, Int. J. Adv. Manuf. Technol. 92, 2439-2462 (2017)

Q1 7. M. Bambach, Modeling of optimization strategies in the incremental $\mathrm{CNC}$ sheet metal forming process. AI P 1969-1974 (2004)

8. M. Bambach, M. Cannamela, M. Azaouzi, G. Hirt, J.L. Batoz, Computer-aided tool path optimization for single point incremental sheet forming, in: Advanced Methods in Material Forming, Springer Berlin Heidelberg, Berlin, Heidelberg, 2007

9. L. Filice, L. Fratini, F. Micari, Analysis of material formability in incremental forming, CIRP Ann. 51, 199-202 (2002)

10. M.-S. Shim, J.-J. Park, The formability of aluminum sheet in incremental forming, J. Mater. Process. Technol. 113, 654-658 (2001)

11. Y. Kim, J. Park, Effect of process parameters on formability in incremental forming of sheet metal, J. Mater. Process. Technol. 130-131, 42-46 (2002)

12. T. Kim, D. Yang, Improvement of formability for the incremental sheet metal forming process, Int. J. Mech. Sci. 42, 1271-1286 (2000)

13. G. Ambrogio, I. Costantino, L. De Napoli, L. Filice, L. Fratini, M. Muzzupappa, Influence of some relevant process parameters on the dimensional accuracy in incremental forming: a numerical and experimental investigation, J. Mater. Process. Technol. 153-154, 501-507 (2004)

14. M. Ham, J. Jeswiet, Forming limit curves in single point incremental forming, CIRP Ann. 56, 277-280 (2007)

15. J. Jeswiet, J.R. Duflou, A. Szekeres, Forces in single point and two point incremental forming, Adv. Mater. Res. 6-8, 449-456 (2005)

16. J. Duflou, Y. Tunçkol, A. Szekeres, P. Vanherck, Experimental study on force measurements for single point incremental forming, J. Mater. Process. Technol. 189, 65-72 (2007)

17. C.F. Guzmán, J. Gu, J. Duflou, H. Vanhove, P. Flores, A.M. Habraken, Study of the geometrical inaccuracy on a SPIF two-slope pyramid by finite element simulations, Int. J. Solids Struct. 49, 3594-3604 (2012)

18. R. Ben Hmida, S. Thibaud, A. Gilbin, F. Richard, Influence of the initial grain size in single point incremental forming process for thin sheets metal and microparts: experimental investigations, Mater. Des. 45, 155-165 (2013)

19. S.P. Shanmuganatan, V.S. Senthil Kumar, Modeling of incremental forming process parameters of $\mathrm{Al} 3003(\mathrm{O})$ by response surface methodology, Procedia Eng. 97, 346-356 (2014)

20. S. Gatea, H. Ou, G. McCartney, Review on the influence of process parameters in incremental sheet forming, Int. J. Adv. Manuf. Technol. 87, 479-499 (2016)
21. Y. Li, H. Lu, W.J.T. Daniel, P.A. Meehan, Investigation and optimization of deformation energy and geometric accuracy in the incremental sheet forming process using response surface methodology, Int. J. Adv. Manuf. Technol. 79, 2041-2055 (2015)

22. J. Pathak, A brief review of Incremental sheet metal forming, Int. J. Latest Eng. Manag. Res. 2, 35-43 (2017)

23. H. Arfa, R. Bahloul, H. BelHadjSalah, Finite element modelling and experimental investigation of single point incremental forming process of aluminum sheets: influence of process parameters on punch force monitoring and on mechanical and geometrical quality of parts, Int. J. Mater. Form. 6, 483-510 (2013)

24. X. Li, K. Han, P. Xu, H. Wang, D. Li, Y. Li, Q. Li, Experimental and theoretical analysis of the thickness distribution in multistage two point incremental sheet forming, Int. J. Adv. Manuf. Technol. 107, 191-203 (2020)

25. Y. Li, X. Chen, W. Zhai, L. Wang, J. Li, G. Zhao, Effects of process parameters on thickness thinning and mechanical properties of the formed parts in incremental sheet forming, Int. J. Adv. Manuf. Technol. 98, 3071-3080 (2018)

26. S. Zhang, G.H. Tang, Z. Li, X. Jiang, K. Li, Experimental investigation on the springback of $\mathrm{AZ} 31 \mathrm{~B} \mathrm{Mg}$ alloys in warm incremental sheet forming assisted with oil bath heating, Int. J. Adv. Manuf. Technol. 109, 535-551 (2020)

27. S. Thibaud, R. Ben Hmida, F. Richard, P. Malécot, A fully parametric toolbox for the simulation of single point incremental sheet forming process: numerical feasibility and experimental validation, Simul. Model. Pract. Theory 29, 32-43 (2012)

28. S. Dejardin, S. Thibaud, J.C. Gelin, G. Michel, Experimental investigations and numerical analysis for improving knowledge of incremental sheet forming process for sheet metal parts, J. Mater. Process. Technol. 210, 363-369 (2010)

29. C. Henrard, C. Bouffioux, L. Duchêne, J.R. Duflou, A.M. Habraken, Validation of a new finite element for incremental forming simulation using a dynamic explicit approach, Key Eng. Mater. 344, 495-502 (2007)

30. C. Henrard, A.M. Habraken, A. Szekeres, J.R. Duflou, S. He, A. Van Bael, P. van Houtte, Comparison of FEM simulations for the incremental forming process, Adv. Mater. Res. 6-8, 533-542 (2005)

31. C. Henrard, C. Bouffioux, P. Eyckens, H. Sol, J.R. Duflou, P. Van Houtte, A. Van Bael, L. Duchêne, A.M. Habraken, Forming forces in single point incremental forming: prediction by finite element simulations, validation and sensitivity, Comput. Mech. 47, 573-590 (2011)

32. A.L. Gurson, Continuum theory of ductile rupture by void nucleation and growth: part I-yield criteria and flow rules for porous ductile media, J. Eng. Mater. Technol. 99, 2 (1977)

33. V. Tvergaard, Influence of voids on shear band instabilities under plane strain conditions, Int. J. Fract. 17, 389-407 (1981)

34. V. Tvergaard, On localization in ductile materials containing spherical voids, Int. J. Fract. 18, 237-252 (1982)

35. V. Tvergaard, Influence of void nucleation on ductile shear fracture at a free surface, J. Mech. Phys. Solids 30, 399-425 (1982)

36. V. Tvergaard, A. Needleman, Analysis of the cup-cone fracture in a round tensile bar, Acta Metall. 32, 157-169 (1984)

37. E. Voce, A practical strain-hardening function, Metallurgica 51, 219-226 (1955) 
38. Y.-R. Oh, H.-S. Nam, Y.-J. Kim, N. Miura, Application of the GTN model to ductile crack growth simulation in throughwall cracked pipes, Int. J. Press. Vessels Pip. 159, 35-44 (2018)

39. T. Marwala, Finite-element-model updating using computional intelligence techniques: applications to structural dynamics, Springer, London, 2010

40. G. Cricrì, A consistent use of the Gurson-TvergaardNeedleman damage model for the R-curve calculation, Frat. Ed Integrità Strutt. 7, 161-174 (2013)

41. M. Gologanu, J.-B. Leblond, G. Perrin, J. Devaux, Recent extensions of Gurson's model for porous ductile metals, in: P. Suquet (Ed.), Continuum Micromechanics, Springer Vienna, Vienna, 1997, vol. 377

42. A. Benzerga, Micromechanics of coalescence in ductile fracture, J. Mech. Phys. Solids 50, 1331-1362 (2002)

43. S.M. Keralavarma, A.A. Benzerga, A constitutive model for plastically anisotropic solids with non-spherical voids, J. Mech. Phys. Solids 58, 874-901 (2010)

44. A.A. Benzerga, J.-B. Leblond, A. Needleman, V. Tvergaard, Ductile failure modeling, Int. J. Fract. 201, 29-80 (2016)

45. K. Nahshon, J.W. Hutchinson, Modification of the Gurson model for shear failure, Eur. J. Mech. A Solids 27, 1-17 (2008)
46. M. Ould Ouali, Relevance of incorporating cavity shape change in modelling the ductile failure of metals, Math. Probl. Eng. 2018, 1-9 (2018)

47. J.I.V. de Sena, C.F. Guzman, L. Duchene, A.M. Habraken, R.A.F. Valente, R.J. Alves de Sousa, Numerical simulation of a conical shape made by single point incremental, 2013, $\mathbf{Q 3}$ 852-855

48. C.F. Guzmán, S. Yuan, L. Duchêne, E.I. Saavedra Flores, A. M. Habraken, Damage prediction in single point incremental forming using an extended Gurson model, Int. J. Solids Struct. 151, 45-56 (2018)

49. D.W. Jung, Static-explicit finite element method and its application to drawbead process with spring-back, J. Mater. Process. Technol. 128, 292-301 (2002)

50. H. Zhu, X. Chang, D.W. Jung, The generation of the forming path with the springback compensation in the CNC incremental forming, Int. J. Mater. Form. 11, 455-470 (2018)

51. J. Goupy, L. Creighton, Introduction aux plans d'expériences, Dunod, L'Usine nouvelle, Paris, 2006

52. J. Li, S. Li, Z. Xie, W. Wang, Numerical simulation of incremental sheet forming based on GTN damage model, Int. J. Adv. Manuf. Technol. 81, 2053-2065 (2015)

Cite this article as: Belouettar Karim, Ould Ouali Mohand, Zeroudi Nasereddine, Thibaud Sébastien, Investigation of the influence of incremental sheet forming process parameters using response surface methodology, Metall. Res. Technol. Vol, No $(2021)$ 


\section{Author Queries}

Q1 Please provide volume number for Ref. [7].

Q2 Please provide editors name and page range for Ref. [8].

Q3 Please provide journal title and volume number for Ref. [47]. 